\title{
Roentgenological Examinations of the Motility of the Stomach in Healthy Individuals during Rest and Motion"
}

\author{
by \\ Aage Als Nielsen \\ Assistant to the Roentgenological Department
}

The motility of the stomach, and particularly that part which purely concerns the emptying, has been an important and very much discussed subject in the roentgen diagnosis of gastro-enterological conditions. In the beginning these examinations were made with the different retention meals followed by lavage, and later studied by the roentgenological method. Attention was early called to the question as to whether there was any difference in the motility of the sick stomach or of the healthy one, and what difference it made whether the individual was at rest, in motion, or in a right or left-sided prone position. As to this latter question the authorities have not agreed and in the following a few examples are mentioned.

KJERGAARD (Denmark), 1888, found that the emptying takes place quickest and easiest with patients sleeping and lying in bed,

Ziegelroth (Inaug. Dissert. Halle, 1902) denies, on the other hand, every influence of sleep, nearly in agreement with

FLEJSHER (Berl. klin. Wochenschrift, 1892) who finds sthe emptying * of the same duration, whether the individual is up or in bed; delayed, if the person examined is in motion after the meal.

v. MEering (Therapie der Gegenwart, 1902), on the contrary, finds that the emptying takes place quickest when lying in a right-sided position or walking quickly. The emptying is somewhat slower when lying on the back, and slowest when the individual is sitting, standing, walking slowly or lying on the left side.

\footnotetext{
* Read at the II meeting of the Nordisk förening för medicinsk radiologi at Copenhagen, Sept. 1921.
} 
Numerous examinations have been made by the roentgenologist, regarding the normal time it takes the stomach to empty, since this question was first raised within the science of roentgenology; however, there has been slight notice taken of the abovementioned circumstances, as the persons examined have nearly always been sitting or in slight motion.

JoLASSE (Fortschritte Bd. XI, page 47) examined the same individual after lying on the right side, on the back, and walking, but found no difference in the time of emptying.

On the other hand, Marcowic and Perussia found that the stomach emptied itself quicker when the person examined made medium-strong movements than when resting (Reported in Med. Klinik 1910-14., a work not at my disposal).

A comparison between ambulatory patients (Dr. BORGBJERG's) and patients of the Municipal Hospital of Copenhagen was striking. The stomach of the ambulatory patient had emptied after two-three hours, while, in the patients lying in bed, even in cases where serious gastric disturbance was not discovered, retention was often found after four hours. In view of these facts an examination of this question seemed desirable. The only essential difference in the two groups was, that the firstnamed walked about or sat during the examination, the lastnamed lay quietly in bed.

Through Professor EHLeR's kindness I succeeded in examining twenty individuals that had never presented any clinical symptoms of disturbances in the digestive organs. These patients were suffering from no other disease than a beginning syphilis, the examination being made shortly after the appearance of the primary chancre. The tests were made in such a manner that the patients were fluoroscoped immediately after taking 300 grammes of rice flour gruel $+100 \mathrm{gr}$. barium sulphate. (Our Dept. ordinary retention-meal and the same as used for Dr BorGBJERG's patients). In the first experiments the examined patients went to bed, stayed there for $2-2 \frac{1}{2}$ hours, got up and walked to the roentgen room. If there was any retention they returned to bed, but were examined in about half an hour (according to the amount retained) and thereafter each half hour until the stomach was empty. If it was doubtful whether a gruel shadow belonged to the stomach or intestine, the patient was given a barium tablet. This tablet could be seen in the shadow and moved with it, if the gruel was in the stomach.

In two-three days, after the intestines were entirely empty of the meal, the patient was re-examined in the same manner. However, during this period the patient was up and about.

A disturbing factor in these examinations was that the patients lying 
in bed had to get out of bed, dress, walk to and from the roentgen room, undress and probably repeat this more than once. However, circumstances did not permit us to do otherwise. I am therefore of the opinion that the emptying time of the patients lying in bed is not absolutely determinative, as the difference is too small; yet they show with relative clearness in which direction the facts may be found.

Ten men and ten women were examined, the lastnamed not during the menstrual or pre-menstrual period. LübrNs examinations (Fortschr. Bd. XXIII, page 501) have shown that during these periods there may be considerable delay in the emptying.

The table shows the following results.

The stomach was emptied

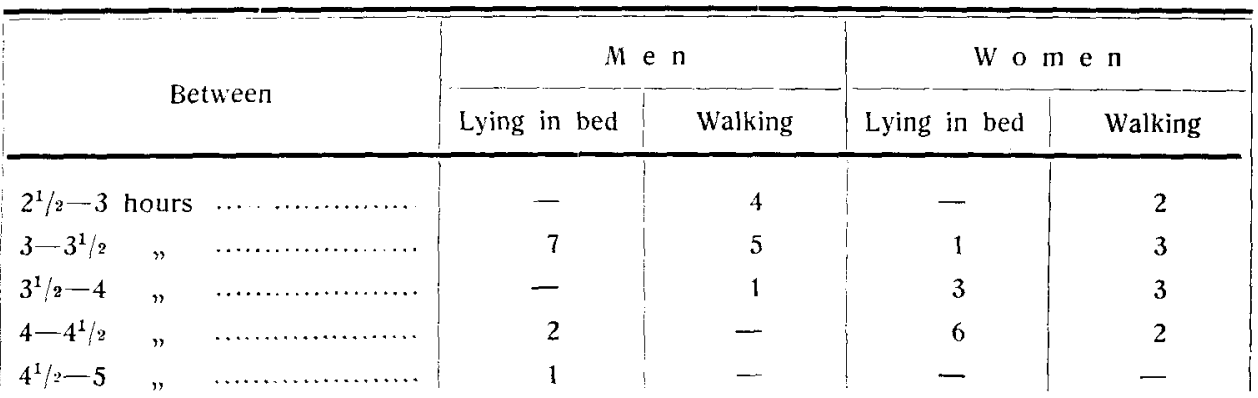

By studying the above table we find that, in 7 out of 10 men, the emptying time was shorter when walking than when lying. The difference was

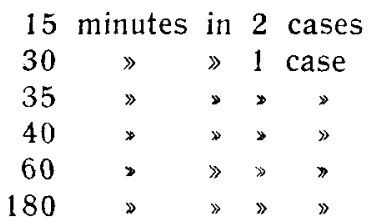

In regard to the women, there were two cases in which the emptying took place respectively 20 and 30 minutes quicker when lying than when walking. With two there was no difference; in the remaining 6 the stomach emptied quicker when walking than lying, the difference being

\begin{tabular}{|c|c|c|c|c|}
\hline 30 & minutes & in & & cases \\
\hline 50 & $»$ & $\gg$ & & case \\
\hline 75 & 》 & 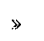 & & cases \\
\hline 125 & 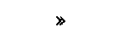 & $\%$ & & case \\
\hline
\end{tabular}


Taking the average difference of all the examined cases, we find that the emptying takes 37 minutes longer for the men lying in bed, and 34 minutes for the women lying in bed. A single case (a man) was examined three times, and constantly found that, when walking about, his stomach emptied half an hour quicker than when lying.

Consequently, there is a distinct difference in the emptying time. The stomach empties faster when the person examined is in motion. A difference which undoubtedly would have been greater, had it been possible to keep the individuals lying in bed, completely at rest during the entire examination.

This examination has made it clear that, in determining normal and abnormal time of emptying, we must consider whether the patient has been at rest or in motion during the examination. A retention of $4-41 / 2$ hours should be considered less abnormal in a patient lying than in an individual in motion.

A few words in conclusion about the supposed times of emptying. Many writers as Kaestle, Schwartz \& Kreuzfuchs, Jolasse, Groedel and WULACH state that barium gruel is evacuated between $21 / 2-31 / 2$ hours. STIERLIN does not always consider a 6 hours' retention to be pathologic; HaudeK does not consider less than $1 / 4$ of the total intake, after 6 hours, of diagnostic value.

In a later series of examinations of these circumstances WISSING found [Ugeskrift for Læger (Denmark), 1921, No. 37] that 5 hours' retention must be considered to be a motor insufficiency. Which seems to agree with the emptying times of the cases I have examined, as shown by the following table:

Out of 10 men lying in bed, the stomach in 7 had emptied within $3^{1 / 2}$ hours; the remaining 3 within 5 hours.

In 9 walking, the stomach emptied within $3 \frac{1}{2}$ hours, 1 in 4 hours.

In women, the stomach emptied somewhat slower than in men, a fact KAESTLE earlier pointed out, and which again is noticeable in our series of patients, at rest as well as in motion.

Out of 10 women lying in bed, the stomach emptied within $3 \frac{1}{2}$ hours in one only, within 4 hours in three and within $4 \frac{1}{2}$ hours in the remaining 6 .

In motion, in five out of these same women, the stomach emptied in $3^{1 / 2}$ hours, five within $4^{1 / 2}$ hours in the remaining.

It appears, then, that, in women lying in bed, the stomach ought to empty in 5 hours. This amount of time can undoubtedly be decided upon as the normal maximum time. 
ROENTGENOL. EXAMINATIONS OF THE MOTILITY OF THE STOMACH 383

\section{Summary}

The author has examined 20 stomachs of healthy individuals - 10 men and 10 women - following the intake of an opaque meal consisting of 300 grammes of rice flour gruel and 100 grammes of barium sulphate. The individuals were partly at rest and partly in motion. He has found that

1) The stomach empties quicker during motion than rest.

2) In women, the stomach empties somewhat slower than in men, both in motion and at rest,

3) The stomach empties normally at rest within 5 hours' intake of opaque meal.

I wish to thank the chief of our department, Prof. J. F. Fischer, for the great willingness with which he placed his department at my disposal; also Prof. EHLers for permission to use patients from his department. 